\title{
Emily Aloiz; Janet G. Douglas, Alexander Nagel. "Painted plaster and glazed brick fragments from Achaemenid Pasargadae and Persepolis, Iran"
}

\section{Astrid Nunn}

\author{
(2) OpenEdition \\ Journals \\ Édition électronique \\ URL : http://journals.openedition.org/abstractairanica/46201 \\ DOI : 10.4000/abstractairanica.46201 \\ ISBN : 1961-960X \\ ISSN : 1961-960X \\ Éditeur : \\ CNRS (UMR 7528 Mondes iraniens et indiens), Éditions de l'IFRI
}

Référence électronique

Astrid Nunn, «Emily Aloiz; Janet G. Douglas, Alexander Nagel. "Painted plaster and glazed brick fragments from Achaemenid Pasargadae and Persepolis, Iran" », Abstracta Iranica [En ligne], Volume 37-38-39 | 2018, document 74, mis en ligne le 30 décembre 2018, consulté le 28 septembre 2020 URL : http://journals.openedition.org/abstractairanica/46201 ; DOI : https://doi.org/10.4000/ abstractairanica.46201

Ce document a été généré automatiquement le 28 septembre 2020.

Tous droits réservés 


\title{
Emily Aloiz; Janet G. Douglas,
} Alexander Nagel. "Painted plaster
and glazed brick fragments from
Achaemenid Pasargadae and
Persepolis, Iran"

\author{
Astrid Nunn
}

\section{RÉFÉRENCE}

Emily Aloiz; Janet G. Douglas, Alexander Nagel. "Painted plaster and glazed brick fragments from Achaemenid Pasargadae and Persepolis, Iran”, Heritage Science, 2016/4, 10 p. Open Access: https://heritagesciencejournal.springeropen.com/articles/10.1186/ s40494-016-0072-7

140 fragments de plâtre peint et de briques à glaçure fouillés par Ernst Herzfeld entre 1923 et 1928 à Persépolis et Pasargades sont conservés aujourd'hui à la Freer Study Collection at the Smithsonian Institution de Washington DC. Les analyses ont été faites par fluorescence aux rayons X (FRX, XRF). Les fragments de Pasargades recouvraient vraisemblablement les colonnes du Palais $\mathrm{P}$, ceux de Persépolis proviennent d'un sol. Les couleurs étaient appliquées sur un mortier en terre, d'une épaisseur pouvant atteindre jusqu'à quatre cm et elle-même recouverte d'une fine couche grisâtre-jauneverte. Cette couche, une fois peinte en blanc avec du carbonate de calcium, servait de fond aux peintures proprement dites.

2 Les sols de Persépolis étaient d'un rouge foncé fabriqué à l'hématite. Pour les autres couleurs, le "rouge modéré" était du cinabre, le rose de l'hématite, le bleu du bleu égyptien, le vert de la malachite, le blanc de la muscovite et/ou de la kaolinite. Le liant était très vraisemblablement organique. 
3 Le sol de Persépolis était monochrome alors que les motifs de Pasargades étaient géométriques et comportaient des volutes. Quant aux fragments à glaçure, tous de Persépolis et ayant sans doute appartenus à des plaques, les analyses de matériaux indiquent de la faïence pour leur masse et l'emploi de l'antimoine de plomb pour le jaune, du cuivre pour le vert jaunâtre, du fer pour les lignes grises en relief et des terres alcalines pour les lignes blanches en relief. Les fragments sont trop petits pour reconstituer l'entièreté des motifs géométriques. Parmi eux il y avait des cercles cernés de contours en relief.

\section{AUTEURS}

\section{ASTRID NUNN}

Université de Munich 